\title{
The Air University Library Building
}

$\mathrm{P}$ LANNING A MAJOR library building for any large institution is a great challenge to the imagination. When the proposed library represents the first of its kind in a branch of the government, the challenge is even more intriguing. The concept of a military university is unique in the armed forces; such concentration of military library resources in one institution is unique with the U. S. Air Force.

The Air University represents a very logical centralization of the graduate level educational facilities of the U. S. Air Force. In recent years it has been possible to construct an entirely new campus area with the end goal of providing a truly academic atmosphere in which key officers and men of the Air Force will receive the kind of education needed to make them future leaders of the Air Force. In planning the new campus, both the initial and present plans place the Air University Library at the hub of the circular school area. This location tends to sharpen the concept of the library's place not only in the school but in the Air Force. Early in its growth, this library became the central depository for all Air Force-produced materials, and within the first ten years of its life has built up one of the most extensive and most accessible working collections in military science, particularly the application of air power, in the world.

The types of materials represented in the above-mentioned collections provide one of the basic considerations of the program. The types of material used in

Dr. Orne is director, Air University Library, Maxwell Air Force Base, Alabama. this library vary sufficiently from the usual collections of a university library to influence seriously the building plan. The fundamental book collection is comparable to that of any good college library, such as the Lamont Library at Harvard. This part of the book collection is a key factor in establishing the library climate of one of the main reading rooms. The basic book collection is reinforced in depth to research levels in certain areas of the general collections located in the stacks. Periodical titles, now nearing two thousand in number, include many military interest titles, but also represent all areas of subject interest found in any good college or university library. The current working collections in periodicals are served in another reading room adjacent to the general books reading area. The third type of materials might best have been mentioned first, since it represents the largest part of the collections. This is the classified document collection, now approaching six hundred thousand items, and increasing at the rate of fifteen hundred items per week. These materials are served under special conditions in the second large reading area, one which bears little resemblance to the typical library reading room.

A second consideration which demanded attention was the type of use to be made of this library. This depends naturally upon the nature of the public to be served. The users of this library are for the most part quite different from the typical university student. Where the usual university student is immature and relatively unsophisticated, the typical military officer studying at the Air University is a mature person, frequently with family, and normally quite sophis- 
ticated in his outlook. The typical university student plans for a four-year course of study, where ours can count for the most part on not more than ten months. The typical university student already has or very soon acquires a good understanding of libraries, their contents, and their methods of operation. Our students, for the most part, have none of this. Most of them have been away from an academic atmosphere for many years and often they come with little liking for it. Additional problems were created for the building plan by the necessity of handling high peak loads and by the requirement for a large number of individual or small group study areas.

The next factor which required consideration was the problem of achieving architectural beauty within the strictures of government building controls and without offending the sensitivities of fund-responsible officials on the grounds of extravagance or unnecessary decoration. The idea of a library building to cost as much as two million dollars had never before been considered within the military, and even in government circles the very thought of this raised otherwise sophisticated eyebrows. There were government and military regulations limiting types of material, form of structure, utilization of space, and kinds and amount of illumination, and innumerable other special requirements which had to be met. The funding of the building imposed two strict limitations; the first in terms of money-one million dollars - and the second in terms of space70,000 square feet. With construction services consuming 15 per cent of the available funds, there remained some $\$ 850,000$ with which to build a library of 70,000 square feet. Simple arithmetic reveals a potential cost of approximately $\$ 12$ per square foot.

A glance at the campus plan reveals a broad $\mathrm{T}$-shaped configuration representing the portion of the library now in use. The original plan contemplated an H-shaped building of 140,000 square feet on the same site. Actually what we have is the first half of the building so designed and located that the second half can be added at any time without interrupting current operations within the present structure. The orientation of the library presents it facing the entrance to the campus area, where it dominates by elevation and design as the focal point of the entire school area. Since fund limitations did not permit exterior decoration to achieve architectural elegance, the architect set out to accomplish by mass and line what we could not do with marble and ornamentation. The design of the building is without fenestration in all reading areas, the only glass being on the front and in a few windows at the rear of the building. The long, low lines created by the reading rooms on either side of the central hall tend to heighten the heavy vertical lines rising at the entrance.

The building has a lofty, spacious lobby leading to an entrance hall, both designed to provide large exhibit space. The top lighting in these two areas is full luminous ceiling which provides virtually shadowless illumination of displays. Since the exposure of this entrance area is south, the glass is tinted to prevent daytime glare. Cast aluminum hardware combined with full glass doors represents one of very few luxuries in the design.

The entrance hall opens into three areas. On the left hand, doors open into a combined circulation-reference area, separated from the main reading room by another set of full glass doors. One goes thus from the entrance hall into a working space where all noise-making activities are concentrated. The circulation desk, general reference service, use of the catalogs, and the basic reference collections are all here. Access to the stacks overhead is free and open either by elevator behind the circulation desk 


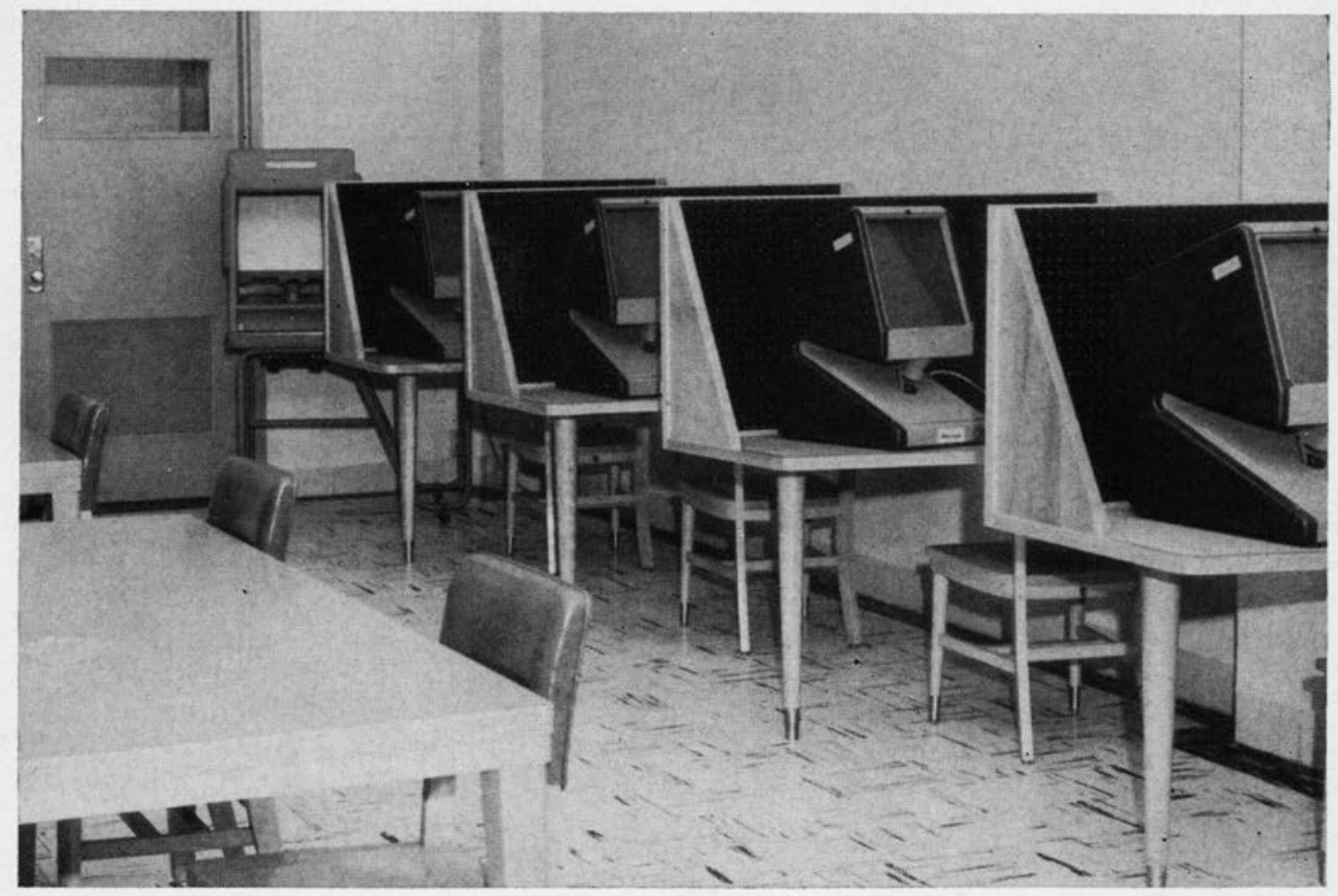

One section of documents reading room in Air University Library

or by stairs off the rear corridor. Beyond this general work and control space, one enters the reading room. It is organized as an ideal study room, divided into numerous small alcoves and discrete units for individual or small group study. The alcoving and divisions are created by using double-faced, varyingheight bookshelves as separators, at the same time providing adequate shelving for the full college collection of books. About forty thousand volumes are housed in this area, the best and latest in every subject field. This collection is renewed continuously by the substitution of new books added to the library.

The periodical reading room adjoins the general reading room. It serves current issues of all journals received and also has at hand the last five to ten years of the most used journals in bound volumes. All periodical indexes, including our own Air University Periodical Index, provide immediate guides to the contents of the collection. This room is staffed by librarians who attend directly to the research needs of the patron. Their function is solely in the area of reference; all processing work is done elsewhere. Two other small units are located within or adjoining the genera? reading room, one being the Authority Collection and the other the Rare Book Room. The former is a heavily used type of material in military activities; the latter is chiefly a repository for unusual gifts to the Air University.

On the right from the entrance hall lies the documents reading room. In this no materials are in sight. It is equipped solely with tables, chairs, carrels, and numerous microfilm-reading machines. The whole area consists of one large room, one medium-size room and fourteen small seminar-type rooms. All available wall spaces are utilized for individual study carrels. Each carrel is provided with a strip microfilm reader. Other types of readers are located throughout nearby spaces. The materials 
used in this room are housed in an adjoining vault, which lies behind the service counter. The vault consists of two levels of steel stack in which documents are filed in transfer cases such as those used in the National Archives and the Library of Congress. The user presents his request for materials to the desk and is issued what he needs, following close identification. Once he has withdrawn the item or items, he is solely responsible for their care. Nearly all of the material used here is security classified and can be made available only under certain conditions. At the same time, the rooms themselves are not secure areas. They are open to any who need the kind of study space provided.

Returning to the central entrance hall, straight ahead lies the technical processing area and services. On either side of the central corridor one finds janitor rooms, telephone booths, washrooms, machinery rooms, and the spacious quarters of the acquisitions and cataloging operations. Located at the end of the corridor are the service elevator and the supply unit. Thus, at the rear entrance, which opens onto a freight dock, and immediately adjacent to the back door, the message center, post office and supply functions are located nearest to the point where materials enter the library. In summary, the above description of the first floor areas began at the front door with the approach of the library user. It ended at the back door with the receipt of library materials.

The second floor of the library is devoted entirely to two functions, the bookstack area and the principal operations of the Audio-Visual Center. The bookstack consists of a unit approximately 100 feet square yielding nearly 10,000 square feet of floor space. The ceiling height will accommodate two levels of stack $71 / 2$ feet high. In the initial stage, only the first level of stack was provided with shelving. The second level remains largely a storage area. Each level will handle approximately two hundred thousand volumes. This provides amply for the current collection of the Air University Library. The stack is maintained as an open part of the library accessible either by elevator or stairs and also furnished with carrels and tables for study in place. In addition to the usual services, the remainder of this floor is devoted to the headquarters offices of the Audio-Visual Center, the film library, duplicating services, and the Cartographics Branch.

The Cartographics Branch maintains and services a massive collection of maps of all kinds. Close to a quarter of a million maps are maintained currently and their use is directed by two trained cartographers and a number of cartographic assistants. This stock of maps is used largely in teaching and in the writing of student or research papers. The material is regarded as expendable, being provided through central supply and replenished as stock diminishes. Not only military maps but numerous commercial types of maps are obtained or produced for whatever needs arise. Maps are frequently modified by the cartographers to produce a desired effect. When cartography alone cannot achieve what is needed, the services of a Graphics Unit or the Photographic Laboratory may also be called into action. The latter two units alone remain outside the library.

The film library maintains a normal stock of something over two thousand films, together with three preview rooms and numerous workshop areas for the care and maintenance of both film and machines used with film. This film library is a major agency within the Air Force-wide film organization, being charged with serving not only the Air University school interests and the Command, but also a fairly broad geographical area surrounding us. In addition to the standing collection, the library draws upon the entire list of film productions within the government and rents any 
commercial film needed. It is directed by a trained librarian film specialist and is heavily used in the teaching program.

The headquarters offices of the AudioVisual Center provide the focus for the combined efforts of all units of this organization and give promise of the best possible coordination of the varied means and devices available to the audiovisualist for presenting educational materials in the best possible form and by the most effective means. With central direction of all audio-visual services, an instructor can have the benefit of combined photographic, cartographic, and graphic operations.

The above brief description of building arrangement is useful primarily as a background for the presentation of certain notable advances in library use which are, in a sense, built into the structure of the library. The first of these is represented in the general reading room. Remembering that this is a library and a center of study for a student body of approximately two thousand military officers and men, one might expect to find a fairly large, barren study hall with military manuals, regulations, and military history lining the walls. One might also expect to find a study hall rigorously disciplined and possibly limited in use by guards at the door. One does find here precisely the opposite. The general reading area is open and inviting. Entrance is through full glass doors, and the first view of the area has been made even more inviting by attractive utilization of casual reading areas, mural decoration, and appealing colors. Supervision of this area is kept to an absolute minimum. Noise is also reduced by the alcoving and separation of areas; the arrangement is such that there is no distracting traffic-way. People move in and out of the room without disturbing others, and it is easily possible to find the kind of seat preferred in almost any area of the room.

As mentioned briefly before, the book collections which literally surround the user have no resemblance to the material described above. This collection contains the best books on every subject available in the library in modest numbers. Each shelf is routinely scrutinized at least once a month by a professional member of the staff assigned to certain subject areas. Older or less useful books are withdrawn and retired to the stacks, while new books move in steadily to take their places. Classic works of literature and art of all countries are found in translation. In biography, the best biographies of men and women from all walks of life stand side by side. In the sciences, the latest editions and the best standard works are always at hand. In religion and philosophy, all beliefs and systems are reasonably well represented.

All of this represents a notable advance, not only in the concept of a military library, but in the academic librarianship of our country. The idea of the college-level collection in the Lamont Library of Harvard was an outgrowth of a typical college library in any of the small colleges of our country: The concept of the home atmosphere study area reaches its highest peak in this kind of reading room, where the user can freely make all the choices. He can decide what kind of seat he wants to use or what size of table he prefers. He can decide if he wants to be located in a corner or out in the open. He can decide if he wants to be surrounded by books of science or art. He moves in and out without supervision or direction, and in very short order feels completely at home. Without windows, external activities do not distract.

A second noteworthy advance grew out of the peculiar requirements of document handling. Massive acquisitions of security classified documents demanded a condensed form of storage. Secure space is costly to provide and maintain, and the endless flow of material requiring such space gives one pause. The first 
space economy was obtained by utilizing library steel shelving instead of fourdrawer file cases. This practice is already used in the National Archives and other comparable collections. The major economy was obtained by establishing a continuous program of conversion to microfilm and the widespread use of it by our public. Three cameras work full time filming current and retrospective files; two other cameras are applied to the current incoming historical files. Both negative and positive are made, the negative remaining in the laboratory as a master for reproduction. When the documents have been filmed, the originals are destroyed. The positive copy of the film is used in the library. It may be kept on a roll if it is a long item or one seldom used. Most documents on film are cut into strips and mounted in a strip film card of letter or legal size. Current models of flat film readers are available throughout the document reading area, and are so simple to use that we have found no appreciable objection to using microfilm. New roll-type readers are mechanized and versatile to such a degree that even roll-type microfilm is readily accepted. There are many other advantages which could be adduced further to demonstrate the value of this method of serving and handling difficult materials, but the essential advance lies in the swift, facile, and accepted use of microfilm without prejudice by a very large public. This use is no longer experimental; for three years our patrons have been using materials in this form. It is not visionary to foresee the time when each library reader's place will be provided with a versatile device for reading microphotographic copies of all materials needed.

The third and last notable advance found in this building lies in the amazing gains made in the use of Audio-Visual services when juxtaposed and closely coordinated with library materials and services. The first step in this direction was taken when the Air University, in its wisdom, placed all Audio-Visual activities within the library organization. Graphic Aids, the Film Library, Cartographic services, and the Photographic Laboratory are all centrally directed and coordinated with other library operations. In the new library building, it is now possible for a student or faculty member not only to locate all useful material regardless of form of presentation, but also to have this material copied, enlarged, reduced, converted to another form, or combined with other material in whatever form it can best be used. Thus, in brief, the library has within its facilities not only all materials needed, but also every possible means or combination of means for presenting or representing those materials.

Just as any new library building very soon shows its small weaknesses, so has ours. It has taken some time to settle the proper distribution of heat and cold; some cracks have appeared where none should be; inadequate provision was made for coats and hats. The major complaint pleases us beyond measure: there are not enough seats in the library. Counter measures are always ready in a military situation. We have placed our order for more chairs and will strive to make this last complaint a recurring one. As we succeed in this, our library in this sense can measure a part of its success. Conversely, we measure our success in the areas of the three notable advances cited earlier by the lack of notice. When changes in methods or materials are introduced in a fairly standardized field without creating a commotion, without disrupting established habits, and with unquestioning acceptance, lack of notice is in itself a mark of success. No matter how we seek to measure the success of our new building or the library's operations, it is already abundantly clear that the new building and the working relationships built into it are having even greater effects than anticipated. 